\title{
Characteristics, determinants, and spatial variations of ambient fungal levels in the subtropical Taipei metropolis
}

\author{
Yi-Hua Wu ${ }^{\mathrm{a}}$, Chang-Chuan Chan ${ }^{\mathrm{b}}$, Carol Y. Rao ${ }^{\mathrm{c}}$, Chung-Te Lee ${ }^{\mathrm{d}}$, \\ Hsiao-Hsien Hsu ${ }^{\mathrm{e}}$, Yueh-Hsiu Chiu ${ }^{\mathrm{e}}$, H. Jasmine Chao ${ }^{\mathrm{a}, *}$ \\ ${ }^{\mathrm{a}}$ Graduate Institute of Public Health, Taipei Medical University, $250 \mathrm{Wu}$-Hsing Street, Taipei, Taiwan 110, ROC \\ ${ }^{\mathrm{b}}$ Institute of Occupational Medicine and Industrial Hygiene, College of Public Health, National Taiwan University, \\ No. 17 Xu-Zhou Road, Taipei, Taiwan 100, ROC \\ ${ }^{c}$ Centers for Disease Control and Prevention, 1600 Clifton Road, Atlanta, GA 30333, USA \\ ${ }^{\mathrm{d}}$ Graduate Institute of Environmental Engineering, National Central University, \\ No. 300, Jungda Road, Jhongli City, Taoyuan, Taiwan 320, ROC \\ ${ }^{\mathrm{e}}$ Department of Environmental Health, Harvard School of Public Health, 665 Huntington Ave., Boston, MA 02115, USA
}

Received 17 July 2006; received in revised form 7 October 2006; accepted 16 November 2006

\begin{abstract}
This study was conducted to investigate the temporal and spatial distributions, compositions, and determinants of ambient aeroallergens in Taipei, Taiwan, a subtropical metropolis. We monitored ambient culturable fungi in Shin-Jhuang City, an urban area, and Shi-Men Township, a rural area, in Taipei metropolis from 2003 to 2004. We collected ambient fungi in the last week of every month during the study period, using duplicate Burkard portable samplers and Malt Extract Agar. The median concentration of total fungi was 1339 colony-forming units $\mathrm{m}^{-3}$ of air over the study period. The most prevalent fungi were non-sporulating fungi, Cladosporium, Penicillium, Curvularia and Aspergillus at both sites. Airborne fungal concentrations and diversity of fungal species were generally higher in urban than in rural areas. Most fungal taxa had significant seasonal variations, with higher levels in summer. Multivariate analyses showed that the levels of ambient fungi were associated positively with temperature, but negatively with ozone and several other air pollutants. Relative humidity also had a significant non-linear relationship with ambient fungal levels. We concluded that the concentrations and the compositions of ambient fungi are diverse in urban and rural areas in the subtropical region. High ambient fungal levels were related to an urban environment and environmental conditions of high temperature and low ozone levels.

(C) 2006 Elsevier Ltd. All rights reserved.
\end{abstract}

Keywords: Aeroallergens; Aerobiology; Bioaerosols; Culturable fungi; Subtropical

\section{Introduction}

Aeroallergens, such as fungal spores and pollens, are ubiquitous in our daily environments (Burge

\footnotetext{
*Corresponding author. Tel.: + $886227361661 \times 6526$; fax: +886227384831 .

E-mail address: hchao@tmu.edu.tw (H.J. Chao).
}

and Otten, 1999; Burge and Rogers, 2000). Exposures to aeroallergens have been correlated with development of allergic diseases and exacerbation of allergic respiratory symptoms (Anderson et al., 2001; Cakmak et al., 2002; Dales et al., 2004; Herr et al., 2003; Ross et al., 2002; Zureik et al., 2002). More than 80 kinds of fungi were identified as risk factors for allergic respiratory diseases, especially 
Aspergillus fumigatus, Cladosporium herbarum, and Alternaria alternata (Burge and Rogers, 2000). These fungi were also considered important factors causing allergic rhinitis and asthma (Achatz et al., 1995; Kurup et al., 2000). Recently, several studies suggested that outdoor airborne fungal concentration is associated with the increase in admission and emergency visit for asthma exacerbations (Anderson et al., 2001; Dales et al., 2004; Lewis et al., 2000; Newson et al., 2000). Exposure to aeroallergens is a special health concern in Taiwan, because the warm and humid climate in this subtropical area provides favorable environmental conditions for microbial and plant growth. One study reported that $21.5 \%$ asthmatic children in Taipei, Taiwan had allergic reaction to fungi (Chou et al., 2002).

Studies have shown that ambient fungal variations were associated with meteorological conditions (Ho et al., 2005; Troutt and Levetin, 2001; Wu et al., 2004). Troutt and Levetin (2001) found that dry-air spora (e.g., Cladosporium, Alternaria, Epicoccum, Drechslera, Pithomyces, Curvularia and smut spores) were more abundant in warmer climates, and that high humidity facilitated wet-air spora (e.g., ascospores and basidiospores) to release spores. Although several studies have shown that the concentrations of airborne fungi increase with higher temperatures, studies of relationships with other climatic factors and air pollutants have been inconsistent (Angulo-Romero et al., 1999; Burch and Levetin, 2002; Corden and Millington, 2001; Hollins et al., 2004; Katial et al., 1997; Stennett and Beggs, 2004; Troutt and Levetin, 2001). More studies are needed to clarify their complex interactions.

The distributions and determinants of ambient fungi are not well characterized in Taiwan, because most of the early studies that report ambient fungal populations in Taiwan used passive samplers, which over estimate fungal taxa with larger spores (Chao et al., 1962; Han and Chuang, 1981; Han et al., 1976; Lu et al., 1969; Tseng and Chen, 1979). Accordingly, we cannot fully estimate potential health risks associated with aeroallergens in Taiwan. Therefore, we implemented a longitudinal study to monitor ambient fungi in both urban and rural areas in Taipei, Taiwan, using active samplers. Our main goal was to evaluate the spatial and temporal distributions, compositions, and determinants of ambient fungi in a subtropical metropolis.

\section{Materials and methods}

\subsection{Sampling locations}

We collected samples at two monitoring stations of the Taiwan Environmental Protection Administration (Taiwan EPA) in Shin-Jhuang City (SJCity), an urban area, and Shi-Men Township (SMTown), a rural area, in Taipei metropolis, Taiwan. SJCity is an emerging metropolis $\left(121^{\circ} 27^{\prime} \mathrm{E}, 25^{\circ} 02^{\prime} \mathrm{N}\right)$, with an area of $19.7 \mathrm{~km}^{2}$ and approximately 39,000 residents (population density: $19,816 \mathrm{~km}^{-2}$ ). SJCity is an important business and industrial center in Taipei County. The majority of SJCity are residential $\left(5 \mathrm{~km}^{2}\right)$ and industrial areas $\left(3 \mathrm{~km}^{2}\right)$, with $4 \mathrm{~km}^{2}$ of agricultural and park lands. The monitoring station in SJCity is located in a park and close to two major highways with heavy traffic (Lee et al., 2006). SMTown is in northernmost Taiwan $\left(121^{\circ} 06^{\prime} \mathrm{E}, 25^{\circ} 03^{\prime} \mathrm{N}\right)$ with approximately 12,000 inhabitants (population density: $227 \mathrm{~km}^{-2}$ ). The total area of SMTown is $51 \mathrm{~km}^{2}$ and the majority is agricultural land $\left(23 \mathrm{~km}^{2}\right)$ and residential area $\left(1.7 \mathrm{~km}^{2}\right)$. Agricultural, wasteland, forest and park areas occupy $43 \mathrm{~km}^{2}$ of SMTown. The major occupations of the local residents are fishery and farming. The sampling location in SMTown is on seashore and facing East China Sea, with minimal local air pollution sources.

\subsection{Fungal sample collection and analysis}

We collected ambient culturable fungi using duplicate Burkard Portable Air Samplers for Agar Plates (Burkard Manufacturing Co., Rickmansworth, England) and Malt Extract Agar (MEA) from March 2003 to December 2004. The samplers were calibrated before each sampling day at a flow rate of $201 \mathrm{~min}^{-1}$. Air sampling was conducted on Tuesday and Thursday in the last week of every month during the study period. Duplicate 2-min samples were collected three times a day (in the morning, afternoon and evening) at the rural site (SMTown), and twice a day (in the morning and afternoon) at the urban site (SJCity). All collected samples were shipped back to the laboratory immediately and were incubated at room temperature for 7-10 days. All the fungal colonies were identified to the level possible by low power microscopy (generally, to genus), and counts recorded by colony type. We used a positive-hole correction table to adjust colony 
counts and corresponding concentrations (Willeke and Macher, 1999). Concentrations are reported in colony-forming units per cubic meter $\left(\mathrm{CFU} \mathrm{m}^{-3}\right)$. The averages of duplicate samples were used for the subsequent analyses.

\subsection{Environmental parameters}

Hourly air pollution and meteorological data were provided by Taiwan EPA. Meteorological data included temperature, relative humidity $(\mathrm{RH})$, dew point, rainfall, and wind speed. Air pollutant data included sulfur dioxide $\left(\mathrm{SO}_{2}\right)$, carbon monoxide (CO), ozone $\left(\mathrm{O}_{3}\right)$, particulates with aerodynamic diameters less than or equal to $10 \mu \mathrm{m}\left(\mathrm{PM}_{10}\right)$, nitrogen monoxide $(\mathrm{NO})$, nitrogen dioxide $\left(\mathrm{NO}_{2}\right)$, total hydrocarbons (THC), methane $\left(\mathrm{CH}_{4}\right)$, and non-methane hydrocarbons (NMHC). We used the hourly averages of these environmental parameters measured concurrently with fungal sampling for further analysis.

\subsection{Statistical analysis}

We used SAS statistical package (v. 8.0, SAS Institute Inc., Cary, NC, USA) to perform data analysis. Mann-Whitney $U$ test and exact test (if the recovery frequency was $<10$ for either site) were used to examine the differences of the fungal levels between the two sampling locations. We evaluated the relationships between ambient fungi and environmental parameters using multiple regressions. We developed regression models for total fungi and the most prevalent fungal genera observed. To account for the serial correlations of fungal measurements, we used PROC MIXED procedure in SAS with an exponential correlation covariance model. Fungal concentrations were transformed using base-10 logarithm to approximate normality in regression analysis. For concentrations lower than the limit of detection, we used $0.1 \mathrm{CFU} \mathrm{m}^{-3}$ to avoid zero values.

\section{Results}

\subsection{Compositions and concentrations of ambient fungi}

A total of 48 fungal taxa were recovered during 2003-2004 from both sampling locations. Table 1 summarizes the distributions of ambient fungi with more than $5 \%$ recovery frequency during the study period. The most prevalent fungal taxa observed were non-sporulating fungi, Cladosporium, Penicillium, Curvularia and Aspergillus, present in more than $50 \%$ of the samples. Non-sporulating fungi, Cladosporium and Penicillium were the most dominant fungal taxa in both 2003 and 2004.

During the study period, 45 fungal taxa were found at the urban site and 37 taxa were recovered at the rural site. At the urban site, the most prevalent fungi were non-sporulating fungi (recovery frequency $=100 \%)$, Cladosporium $(96.2 \%)$, Curvularia (65.4\%), Penicillium (64.7\%), Aspergillus $(62.4 \%)$, and Alternaria $(42.9 \%)$. The taxa observed most frequently at the rural site were Cladosporium (97.5\%), non-sporulating fungi (95.6\%), Penicillium (73.0\%), Fusarium (45.9\%), Aspergillus (41.5\%), and Curvularia (41.5\%). Total fungi and 9 fungal taxa, including Cladosporium, Curvularia, Aspergillus, Alternaria, Botrytis, Coelomycetes, Leptosphaerulina, Pithomyces, and Bipolaris, had significantly higher concentrations at the urban site than at the rural site $(p<0.05)$ (Table 2). The levels of Penicillium, Fusarium and Sporotrichum, on the contrary, were significantly higher at the rural site. Several fungal taxa were only observed at the urban site, including Rhizopus, Zygomycetes, Mucor, Drechslera, Botryosporium, Periconia, Stachybotrys, Torula and Wallemia. Gliomastix and Gliocladium were only recovered at the rural site.

\subsection{Seasonal variations of ambient fungi}

Fig. 1 shows the temporal variations of total fungi at both sampling sites in 2003 and 2004. Total fungal levels were generally higher in warmer months. During 2003, the highest total fungal levels were observed in June $\left(\right.$ median $\left.=2900 \mathrm{CFU} \mathrm{m}^{-3}\right)$ at the urban site and in July $\left(13,760 \mathrm{CFU} \mathrm{m}^{-3}\right)$ at the rural site. In 2004, total fungal concentrations at both sampling locations peaked in June $\left(4145 \mathrm{CFU} \mathrm{m}^{-3}\right.$ at the urban site and $3191 \mathrm{CFU} \mathrm{m}^{-3}$ at the rural site). Fig. 2 shows the distributions of non-sporulating fungi, the most prevalent fungal category, over the study period. In 2003, the concentrations of non-sporulating fungi were highest in June at the urban site $\left(1111 \mathrm{CFU} \mathrm{m}^{-3}\right)$ and in April at the rural site $\left(1203 \mathrm{CFU} \mathrm{m}^{-3}\right)$. In 2004 , non-sporulating fungi had highest levels in September $\left(1101 \mathrm{CFU} \mathrm{m}^{-3}\right)$ and July $\left(668 \mathrm{CFU} \mathrm{m}^{-3}\right)$ at the urban and rural sites, respectively. Most of the 
Table 1

Descriptive statistics for ambient fungal concentrations $\left(\mathrm{CFU} \mathrm{m}^{-3}\right)$ in Taipei metropolis during 2003 and 2004

\begin{tabular}{|c|c|c|c|c|c|c|}
\hline Fungal categories ${ }^{\mathrm{a}}$ & Freq. $(\%)^{b}$ & Mean & Median & Std. dev. & Min & Max \\
\hline Non-sporulating & 97.6 & 507.48 & 372 & 449.35 & 0 & 2592 \\
\hline Cladosporium & 96.9 & 379.84 & 274 & 350.90 & 0 & 2563 \\
\hline Penicillium & 69.2 & 77.43 & 30 & 127.09 & 0 & 1160 \\
\hline Curvularia & 52.4 & 46.61 & 20 & 78.28 & 0 & 668 \\
\hline Aspergillus & 51.0 & 53.65 & 12 & 186.17 & 0 & 2558 \\
\hline Fusarium & 38.7 & 17.51 & 0 & 32.63 & 0 & 274 \\
\hline Alternaria & 36.6 & 22.90 & 0 & 44.01 & 0 & 307 \\
\hline Yeast & 19.5 & 9.37 & 0 & 23.82 & 0 & 170 \\
\hline Arthrinium & 18.8 & 7.54 & 0 & 24.68 & 0 & 306 \\
\hline Botrytis & 14.0 & 4.95 & 0 & 14.33 & 0 & 100 \\
\hline Coelomycetes & 14.0 & 7.00 & 0 & 27.54 & 0 & 327 \\
\hline Trichoderma & 12.0 & 2.92 & 0 & 8.55 & 0 & 47 \\
\hline Geotrichum & 9.6 & 9.61 & 0 & 58.95 & 0 & 713 \\
\hline Leptosphaerulina & 9.3 & 3.05 & 0 & 11.39 & 0 & 105 \\
\hline Aureobasidium & 8.9 & 3.41 & 0 & 13.07 & 0 & 93 \\
\hline Nigrospora & 8.2 & 2.51 & 0 & 9.83 & 0 & 68 \\
\hline Candida & 7.9 & 2.63 & 0 & 10.05 & 0 & 77 \\
\hline Sporothrix & 7.9 & 3.49 & 0 & 18.22 & 0 & 253 \\
\hline Verticillium & 5.5 & 1.69 & 0 & 8.41 & 0 & 96 \\
\hline Total fungi & 100 & 2257.39 & 1339 & 3221.60 & 0 & 25,935 \\
\hline
\end{tabular}

${ }^{a}$ Other observed fungi (recovery frequency $<5 \%$ ) not included in this table are Pithomyces, Trichophyton, Neurospora, Paecilomyces, Bipolaris, Chaetomium, Sporotrichum, Acremonium, Rhizomucor, Rhizopus, Rhinocladiella, Ulocladium, Zygomycetes, Mucor, Pestalotiopsis, Drechslera, Epicoccum, Exserohilum, Microsporum, Scopulariopsis, Xylohypha, Botryosporium, Gliomastix, Gliocladium, Periconia, Stachybotrys, Torula and Wallemia.

${ }^{\mathrm{b}}$ Frequency was the percentage of samples (total $n=292$ ) with presence of that specific fungal category.

Table 2

Distributions of selected ambient fungi in urban and rural areas during 2003 and 2004

\begin{tabular}{|c|c|c|c|c|c|c|c|c|c|}
\hline \multirow[t]{2}{*}{ Fungal categories $\left(\mathrm{CFU} \mathrm{m}^{-3}\right)^{\mathrm{a}}$} & \multicolumn{4}{|c|}{ Urban $(n=133)$} & \multicolumn{4}{|c|}{ Rural $(n=159)$} & \multirow[t]{2}{*}{$p$-Value ${ }^{\mathrm{b}}$} \\
\hline & Freq. $(\%)^{\mathrm{c}}$ & Mean & Median & Std. dev. & Freq. $(\%)$ & Mean & Median & Std. dev. & \\
\hline Total fungi & 100.0 & 2233.16 & 1643 & 2676.10 & 100.0 & 2277.66 & 1085 & 3623.70 & 0.0122 \\
\hline Cladosporium & 96.2 & 445.70 & 363 & 382.43 & 97.5 & 324.74 & 230 & 312.86 & 0.0015 \\
\hline Penicillium & 64.7 & 53.89 & 23 & 75.89 & 73.0 & 97.11 & 43 & 155.18 & 0.0180 \\
\hline Curvularia & 65.4 & 63.56 & 37 & 94.31 & 41.5 & 32.44 & 0 & 58.41 & $<0.0001$ \\
\hline Aspergillus & 62.4 & 85.62 & 23 & 263.98 & 41.5 & 26.91 & 0 & 63.53 & $<0.0001$ \\
\hline Fusarium & 30.1 & 14.25 & 0 & 37.18 & 45.9 & 20.24 & 0 & 28.11 & 0.0013 \\
\hline Alternaria & 42.9 & 25.15 & 0 & 38.11 & 31.5 & 21.01 & 0 & 48.44 & 0.0411 \\
\hline Botrytis & 24.1 & 8.88 & 0 & 18.86 & 5.7 & 1.66 & 0 & 7.55 & $<0.0001$ \\
\hline Coelomycetes & 18.8 & 9.32 & 0 & 33.09 & 10.1 & 5.06 & 0 & 21.76 & 0.0338 \\
\hline Leptosphaerulina & 13.5 & 4.02 & 0 & 11.23 & 5.7 & 2.24 & 0 & 11.50 & 0.0214 \\
\hline Pithomyces & 7.5 & 4.06 & 0 & 22.07 & 2.5 & 0.75 & 0 & 4.93 & 0.0446 \\
\hline Bipolaris & 6.0 & 3.05 & 0 & 15.63 & 0.6 & 0.38 & 0 & 4.80 & 0.0100 \\
\hline Sporotrichum & 0.8 & 0.59 & 0 & 6.85 & 5.0 & 2.69 & 0 & 13.46 & 0.0395 \\
\hline
\end{tabular}

${ }^{a}$ The fungal taxa included in the table had significantly different concentrations between the two sampling sites.

${ }^{\mathrm{b}}$ Mann-Whitney $U$ test or Exact Test was used to examine the differences of fungal levels between the two sampling locations.

${ }^{\mathrm{c}}$ Frequency was the percentage of samples with presence of that specific fungal category.

predominant fungi had similar seasonal patterns as the total and non-sporulating fungi, with higher levels in warmer months. However, the concentra- tions of Cladosporium peaked both in summer (June-August) and winter (December-January) during the study period (data not shown). 

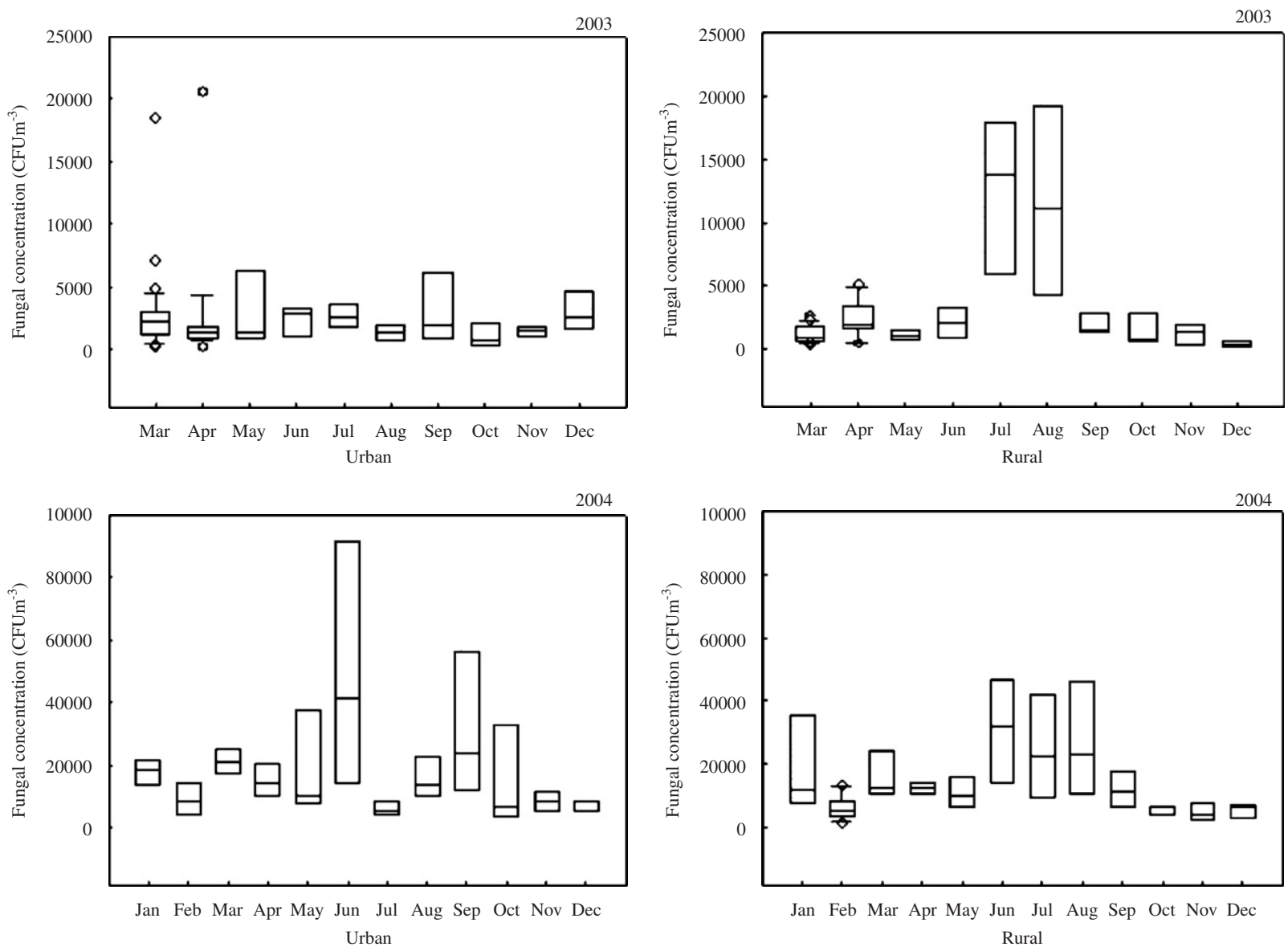

Fig. 1. Seasonal variations of total fungi during 2003 and 2004. The box plots show medians 10th, 25th, 75th, and 90th percentiles and outliers (circles).

\subsection{Associations between ambient fungi and environmental parameters}

During the study period, most of the air pollutants had higher concentrations at the urban area than the rural area (Table 3). Multiple regression models for major fungal taxa and total fungi are listed in Table 4. In the multiple regression models, temperature was the most consistent predictor of fungal concentrations, which had positive correlations with total fungi, Penicillium, Curvularia, and Aspergillus. Total fungi, Cladosporium, Penicillium and Aspergillus were correlated with $\mathrm{RH}$ nonlinearly $\left(\mathrm{RH}+\mathrm{RH}^{2}\right)$. Wind speed was significantly associated with both non-sporulating fungi and Curvularia, yet had diverse effects on their concentrations. Among air pollutants, ozone, $\mathrm{CO}$ and $\mathrm{CH}_{4}$ had significant negative relationships with fungal levels. NMHC, however, was significantly and positively related to non-sporulating fungi. We also found sampling year had significant effects on the levels of total fungi, non-sporulating fungi and Cladosporium.

\section{Discussion}

In this study, we found that total airborne fungal concentrations and diversity of fungal species (as measured by the number of fungal taxa identified) were generally higher in urban than in rural areas. Other gases and particulate pollutants also had higher concentrations at the urban site than the rural site, except $\mathrm{CH}_{4}$ (Table 3). Local turbulence in high traffic locales, such as SJCity, increases fungal spore aerosolization from surrounding environments and increases ambient fungal levels (Lugauskas et al., 2003). SMTown is a rural seaside town with less urban pollution, as indicated by lower air 

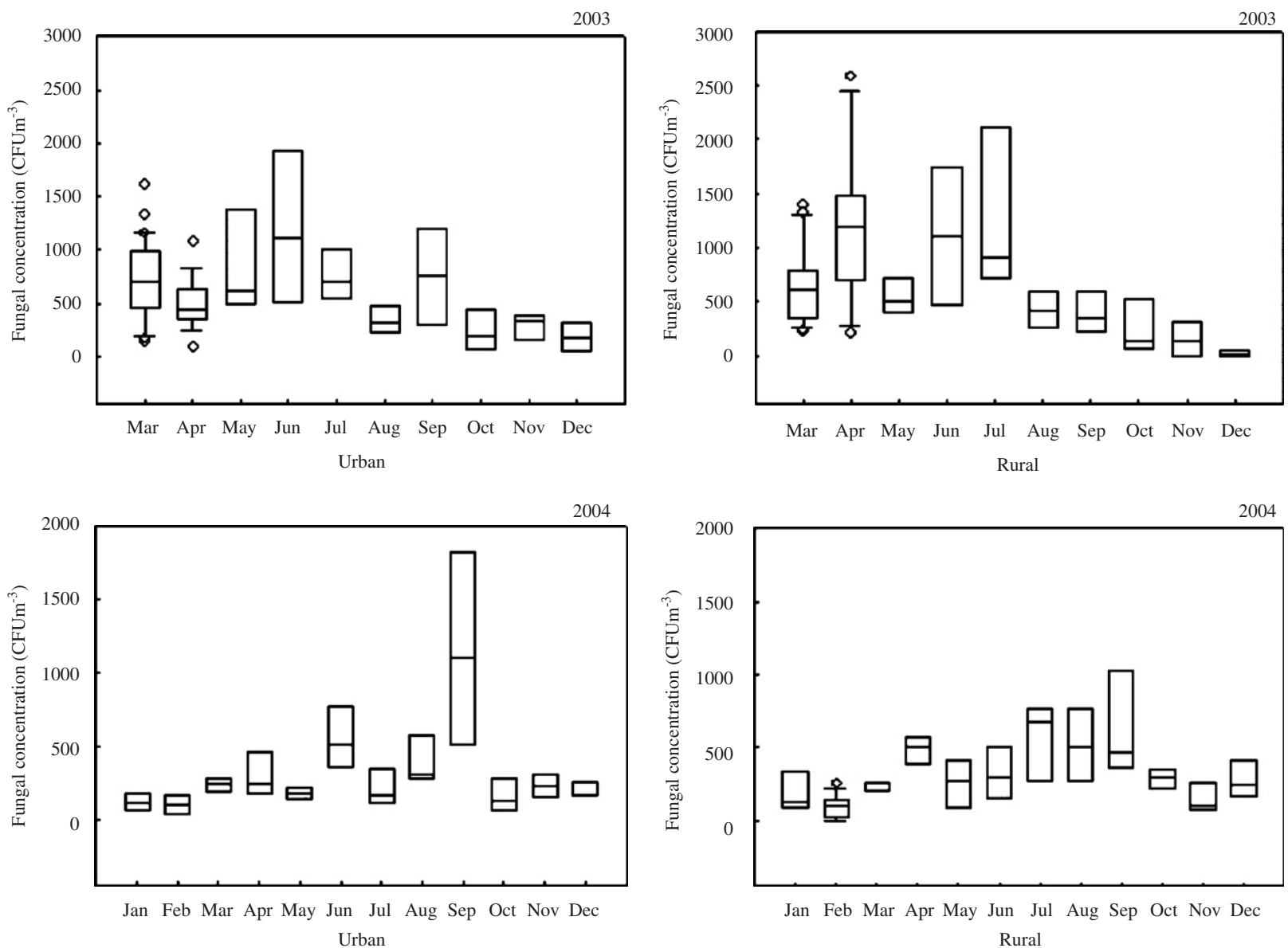

Fig. 2. Seasonal variations of non-sporulating fungi during 2003 and 2004 . The box plots show medians 10th, 25th, 75th, and 90th percentiles and outliers (circles).

Table 3

Distributions of environmental factors in urban and rural areas during 2003 and 2004

\begin{tabular}{|c|c|c|c|c|c|c|c|c|}
\hline \multirow[t]{2}{*}{ Environmental factors } & \multicolumn{4}{|l|}{ Urban } & \multicolumn{4}{|l|}{ Rural } \\
\hline & Mean & Std. dev. & Min & Max & Mean & Std. dev. & Min & Max \\
\hline $\mathrm{SO}_{2}(\mathrm{ppb})$ & 6.9 & 9.2 & 0.0 & 71.2 & 2.7 & 3.01 & 0.0 & 14.0 \\
\hline $\mathrm{CO}(\mathrm{ppb})$ & 639.1 & 333.5 & 0.0 & 2100.0 & 346.4 & 218.7 & 0.0 & 1030.0 \\
\hline $\mathrm{O}_{3}(\mathrm{ppb})$ & 46.7 & 23.4 & 0.0 & 109.0 & 42.3 & 20.9 & 0.0 & 129.7 \\
\hline $\mathrm{PM}_{10}\left(\mu \mathrm{g} \mathrm{m}^{-3}\right)$ & 59.5 & 32.1 & 0.0 & 194.0 & 45.9 & 24.9 & 5.0 & 143.0 \\
\hline NO (ppb) & 3.1 & 4.6 & 0.0 & 44.0 & 2.2 & 3.0 & -0.2 & 14.7 \\
\hline $\mathrm{NO}_{2}(\mathrm{ppb})$ & 24.0 & 12.5 & 0.0 & 64.0 & 9.5 & 7.5 & 0.0 & 46.1 \\
\hline THC (ppb) & 2846.3 & 674.5 & 0.0 & 6632.0 & 2447.8 & 553.5 & 123.0 & 3595.0 \\
\hline NMHC (ppb) & 814.9 & 469.2 & 0.0 & 3300.0 & 180.4 & 118.7 & 0.00 & 664.7 \\
\hline $\mathrm{CH}_{4}(\mathrm{ppb})$ & 2036.2 & 353.0 & 0.0 & 3430.0 & 2267.3 & 517.1 & 50.0 & 3230.0 \\
\hline Wind speed $\left(\mathrm{m} \mathrm{s}^{-1}\right)$ & 2.6 & 1.5 & 0.3 & 6.6 & 3.5 & 2.7 & 0.2 & 13.0 \\
\hline Temperature $\left({ }^{\circ} \mathrm{C}\right)$ & 26.5 & 5.4 & 14.7 & 36.3 & 23.8 & 5.7 & 8.0 & 34.2 \\
\hline Dew point $\left({ }^{\circ} \mathrm{C}\right)$ & 17.9 & 3.8 & 11.0 & 27.7 & 19.9 & 4.1 & 11.9 & 28.3 \\
\hline RH (\%) & 61.0 & 11.0 & 38.0 & 87.1 & 75.5 & 10.5 & 52.7 & 94.9 \\
\hline Rainfall (mm) & 0.06 & 0.43 & 0.00 & 4.40 & 0.14 & 0.88 & 0.00 & 7.40 \\
\hline
\end{tabular}

${ }^{\text {a }}$ Presented data were measured concurrently with the fungal sampling. 
Table 4

Multiple regression models for major fungal taxa

\begin{tabular}{|c|c|c|c|}
\hline & $\beta$ coefficient & SE & $p$-Value \\
\hline \multicolumn{4}{|l|}{ Total fungi } \\
\hline Intercept & 24.3484 & 4.3915 & 0.1136 \\
\hline Sampling year & -0.2445 & 0.0490 & $<0.0001$ \\
\hline Temperature & 0.0159 & 0.0035 & $<0.0001$ \\
\hline $\mathrm{RH}$ & 0.0366 & 0.0169 & 0.0315 \\
\hline $\mathrm{RH}^{2}$ & -0.0003 & 0.0001 & 0.0289 \\
\hline $\mathrm{O}_{3}$ & -0.0048 & 0.0011 & $<0.0001$ \\
\hline \multicolumn{4}{|c|}{ Non-sporulating fungi } \\
\hline Intercept & 34.5579 & 7.4414 & 0.135 \\
\hline Sampling year & -0.3419 & 0.0804 & $<0.0001$ \\
\hline Wind speed & -0.1041 & 0.0174 & $<0.0001$ \\
\hline $\mathrm{CO}$ & -0.8520 & 0.1624 & $<0.0001$ \\
\hline NMHC & 0.4615 & 0.1150 & $<0.0001$ \\
\hline \multicolumn{4}{|l|}{ Cladosporium } \\
\hline Intercept & 21.9816 & 8.1832 & 0.2269 \\
\hline Sampling year & -0.2392 & 0.0915 & 0.0094 \\
\hline $\mathrm{RH}$ & 0.0735 & 0.0324 & 0.0238 \\
\hline $\mathrm{RH}^{2}$ & -0.0005 & 0.0002 & 0.0240 \\
\hline \multicolumn{4}{|l|}{ Penicillium } \\
\hline Intercept & -4.2463 & 2.0714 & 0.2889 \\
\hline Temperature & 0.0264 & 0.0125 & 0.0350 \\
\hline $\mathrm{O}_{3}$ & -0.0137 & 0.0041 & 0.0011 \\
\hline $\mathrm{RH}$ & 0.1447 & 0.0584 & 0.0139 \\
\hline $\mathrm{RH}^{2}$ & -0.0010 & 0.0004 & 0.0197 \\
\hline \multicolumn{4}{|l|}{ Curvularia } \\
\hline Intercept & 0.1206 & 0.6042 & 0.8745 \\
\hline Temperature & 0.0427 & 0.0130 & 0.0011 \\
\hline Wind Speed & 0.0884 & 0.0404 & 0.0296 \\
\hline $\mathrm{CH}_{4}$ & -0.4697 & 0.1922 & 0.0152 \\
\hline \multicolumn{4}{|l|}{ Aspergillus } \\
\hline Intercept & -5.2477 & 2.2438 & 0.2572 \\
\hline Temperature & 0.0453 & 0.0129 & 0.0005 \\
\hline $\mathrm{RH}$ & 0.1605 & 0.0632 & 0.0118 \\
\hline $\mathrm{RH}^{2}$ & -0.0012 & 0.0005 & 0.0131 \\
\hline $\mathrm{CH}_{4}$ & -0.4372 & 0.2198 & 0.0479 \\
\hline
\end{tabular}

pollutant concentrations (Table 3). Year-round strong winds in SMTown may dilute local air pollutants, including ambient fungi, as well. Distributions of local vegetation and types of human activities are diverse in SJCity and SMTown, which also contribute to different concentrations and compositions of fungi in the two areas.

Non-sporulating fungi were the most prevalent taxon found in our study. Non-sporulating fungi are species that do not produce spores under the culture conditions provided, mostly formed of basidiospores and ascospores. Using a Burkard Seven-Day Recording Volumetric Spore Trap, we have found that ascospores and basidiospores are the most prevalent fungal taxa at these same sampling sites (unpublished data). Cladosporium was also one of the most prevalent fungi found in our study, which is consistent with other studies conducted in Taiwan and other regions of the world (Al-Subai, 2002; Asan et al., 2002; Chao et al., 1962; Colakoglu, 2003; Ho, 1996; Ho et al., 2005; Troutt and Levetin, 2001). Penicillium, Aspergillus and Alternaria were also frequently recovered in our study. All these fungal taxa are considered universal fungi and are common pathogens associated with respiratory allergic diseases (e.g., allergic rhinitis and asthma) (Achatz et al., 1995; Al-Suwaine et al., 1999; Burge and Rogers, 2000; Kurup et al., 2000; Singh et al., 1987).

Seasonal fluctuation of fungal concentration is dynamic, affected by various variables including climate, meteorological factors, local vegetation, and human activities (Burge and Rogers, 2000). In our study, most fungal taxa showed significant seasonal variations, with higher concentrations in warmer months. Similar findings were observed in previous studies conducted in other areas of Taiwan, in Porto Alegre, Brazil, a subtropical city, and in Melbourne, Australia, a temperate city (Chao et al., 1962; Han et al., 1976; Ho, 1996; Ho et al., 2005, Mezzari et al., 2002; Mitakakis and Guest, 2001). We found that the concentrations of Cladosporium peaked in both summer and winter. Previous research suggests that the concentrations of Cladosporium peak in both cool and warm seasons in subtropical and tropical areas, because winter is usually warm and humid (the rainy season), which promotes spore production and release (Al-Subai, 2002; Calderon et al., 1997; Sabariego et al., 2000; Al-Suwaine et al., 1999; Bunnag et al., 1982; Fernandez et al., 1998; Hollins et al., 2004; Singh et al., 1987; Vittal and Krishnamoorthi, 1988).

Temperature and humidity are important environmental factors determining fungal survival and growth (Burge and Otten, 1999). Many studies found that outdoor fungal concentrations had a positive correlation with ambient temperatures (Burch and Levetin, 2002; Corden and Millington, 2001; Hollins et al., 2004; Sabariego et al., 2000; Stennett and Beggs, 2004; Troutt and Levetin, 2001). Several studies found that the levels of ascospores, basidiospores and some other fungal spores increased with higher humidity (Burch and Levetin, 2002; Sabariego et al., 2000; Stennett and 
Beggs, 2004; Troutt and Levetin, 2001). However, high humidity also indicates a rainy condition, which could remove ambient fungal spores by both rainout and washout effects, especially for dry-air spora (Burge and Rogers, 2000; Weber, 2003). Therefore, the effects of $\mathrm{RH}$ on ambient fungi were inconsistent in different studies. According to our regression analyses, temperature had positive significant correlations with total fungi, Penicillium, Curvularia and Aspergillus. We also found that RH was significantly related to total fungi, Cladosporium, Penicillium and Aspergillus nonlinearly, possibly due to diverse effects of humidity on spores.

Sampling year was significantly associated with total fungi, non-sporulating fungi and Cladosporium, probably because of climate change or vegetation shift during the study period. Some studies indicated that higher wind speed might cause microorganisms to leave their attached surface and suspend in air (Jones and Harrison, 2004). However, other studies found that higher wind speed decreased fungal concentrations because of atmospheric dilution (Sabariego et al., 2000; Stennett and Beggs, 2004). In this study, we also found inconsistent effects of wind speed on fungal concentrations. Wind speed was positively associated with Curvularia but negatively correlated with nonsporulating fungi.

Ozone was significantly and negatively correlated with total fungi and Penicillium, similar to other studies (Ho et al., 2005; Lin and Li, 2000). Ozone is an "open air factor," toxic to microorganisms in the air (Cox et al., 1973). We also found non-sporulating fungi were positively related to NMHC and negatively associated with $\mathrm{CO}$. Negative associations were observed between $\mathrm{CH}_{4}$ and Curvularia and Aspergillus as well. Because few studies examined the effects of air pollutants on airborne fungi, more research are in need to explore the complex interactions between air pollutants and ambient fungi.

\section{Conclusion}

We conducted a longitudinal monitoring study to characterize ambient fungi in both urban and rural areas in a subtropical metropolis and to examine the interrelationships between fungi, meteorological factors, and air pollutants. Non-sporulating fungi, Cladosporium, Penicillium, Aspergillus and Curvularia were the most prevalent fungal taxa during the study period. Airborne fungal concentrations and diversity of fungal species were generally higher in urban than in rural areas. Ambient temperature was the most consistent environmental factor positively correlated with fungal concentrations. RH and wind speed were also important predictors of fungal levels. Moreover, we found several air pollutants such as ozone, $\mathrm{CH}_{4}$, NMHC and $\mathrm{CO}$ had complex interactions with ambient fungi. Because of the adverse health effects of common fungi, future studies should be conducted to examine the interrelationships between environmental parameters and ambient fungi longitudinally and to investigate the impacts of aeroallergens on public health.

\section{Acknowledgments}

This study was supported in part by Environmental Protection Administration, Executive Yuan, Republic of China (EPA-92-U1L1-02-101, EPA-93L105-02-207).

\section{References}

Achatz, G., Oberkofler, H., Lechenauer, E., Simon, B., Unger, A., Kandler, D., Ebner, C., Prillinger, H., Kraft, D., Breitenbach, M., 1995. Molecular cloning of major and minor allergens of Alternaria alternata and Cladosporium herbarum. Molecular Immunology 32, 213-227.

Al-Subai, A.A.T., 2002. Air-borne fungi at Doha, Qatar. Aerobiologia 18, 175-183.

Al-Suwaine, A.S., Hasnain, S.M., Bahkali, A.H., 1999. Viable airborne fungi in Riyadh, Saudi Arabia. Aerobiologia 15, 121-130.

Anderson, W., Prescott, G., Packham, S., Mullins, J., Brookes, M., Seaton, A., 2001. Asthma admissions and thunderstorms: a study of pollen, fungal spores, rainfall, and ozone. The Quarterly Journal of Medicine 94, 429-433.

Angulo-Romero, J., Mediavilla-Molina, A., Dominguez-Vilches, E., 1999. Conidia of Alternaria in the atmosphere of the city of Cordoba, Spain in relation to meteorological parameters. International Journal of Biometeorology 43, 45-49.

Asan, A., Sen, B., Sarica, S., 2002. Airborne fungi in urban air of Edirne city (Turkey). Biologia, Bratislava 57, 59-68.

Bunnag, C., Dhorranintra, B., Plangpatanapanichya, A., 1982. A comparative study of the incidence of indoor and outdoor mold spores in Bangkok, Thailand. Annals of Allergy 48, 333-339.

Burch, M., Levetin, E., 2002. Effects of meteorological conditions on spore plumes. International Journal of Biometeorology 46, 107-117.

Burge, H.A., Otten, J.A., 1999. Fungi. In: Macher, J. (Ed.), Bioaerosols: Assessment and Control. American Conference of Governmental Industrial Hygienists (ACGIH), Cincinnati, OH, pp. 19:11-19:13. 
Burge, H.A., Rogers, C.A., 2000. Outdoor allergens. Environmental Health Perspectives 108, 653-659.

Cakmak, S., Dales, R.E., Burnett, R.T., Judek, S., Coates, F., Brook, J.R., 2002. Effect of airborne allergens on emergency visits by children for conjunctivitis and rhinitis. The Lancet 359, 947-948.

Calderon, C., Lacey, J., McCartney, A., Rosas, I., 1997. Influence of urban climate upon distribution of airborne Deuteromycete spore concentrations in Mexico City. International Journal of Biometeorology 40, 71-80.

Chao, I.T., Chen, L.F., Shieh, J.T., 1962. Study and survey of aero-allergens of Taiwan-1. Preliminary report of a one-year survey of air-borne pollen and mold spores in the Taipei area. Chinese Medical Journal 9, 233-244.

Chou, T.Y., Wu, K.Y., Shieh, C.C., Wang, J.Y., 2002. The clinical efficacy of in vitro allergen-specific IgE antibody test in the diagnosis of allergic children with asthma. Acta Paediatrica Taiwanica 43, 35-39.

Colakoglu, G., 2003. Airborne fungal spores at the Belgrad forest near the city of Istanbul (Turkey) in the year 2001 and their relation to allergic diseases. Journal of Basic Microbiology 43, 376-384

Corden, J.M., Millington, W.M., 2001. The long-term trends and seasonal variation of the aeroallergen Alternaria in Derby, UK. Aerobiologia 17, 127-136.

Cox, C.S., Hood, A.M., Baxter, J., 1973. Method for comparing concentrations of the open-air factor. Applied Microbiology 26, 640-642.

Dales, R., Cakmak, S., Judek, S., Dann, T., Coates, F., Brook, J., Burnett, R., 2004. Influence of outdoor aeroallergens on hospitalization for asthma in Canada. Journal of Allergy and Clinical Immunology 113, 303-306.

Fernandez, D., Maria Valencia, R., Molnar, T., Vega, A., Sagues, E., 1998. Daily and seasonal variations of Alternaria and Cladosporium airborne spores in Leon (North-West, Spain). Aerobiologia 14, 215-220.

Han, S.H., Chuang, Y.C., 1981. Air-borne fungal spore counts in Taiwan. Chinese Medical Journal 28, 193-196.

Han, S.H., Hsieh, C.F., Tsai, L.C., Chao, H.Y., Chuang, Y.C., Chang, L.Y., 1976. A survey of the air-borne allergens in Taipei. National Science Council Monthly 4, 2396-2399.

Herr, C.E.W., Nieden, A.z., Jankofsky, M., Stilianakis, N.I., Boedeker, R., Eikmann, T.F., 2003. Effects of bioaerosol polluted outdoor air on airways of residents: a cross sectional study. Occupational and Environmental Medicine 60, 336-342.

Ho, H.M., 1996. The outdoor fungal airpora in Hualien (I) - The agar plate method. Taiwania 41, 67-80.

Ho, H.M., Rao, C.Y., Hsu, H.H., Chiu, Y.H., Liu, C.M., Chao, H.J., 2005. Characteristics and determinants of ambient fungal spores in Hualien, Taiwan. Atmospheric Environment 39, 5839-5850.

Hollins, P.D., Kettlewell, P.S., Atkinson, M.D., Stephenson, D.B., Corden, J.M., Millington, W.M., Mullins, J., 2004. Relationships between airborne fungal spore concentration of Cladosporium and the summer climate at two sites in Britain. International Journal of Biometeorology 48, 137-141.

Jones, A.M., Harrison, R.M., 2004. The effects of meteorological factors on atmospheric bioaerosol concentrations - a review. Science of the Total Environment 326, 151-180.

Katial, R.K., Zhang, Y., Jones, R.H., Dyer, P.D., 1997. Atmospheric mold spore counts in relation to meteorological parameters. International Journal of Biometeorology 41 , $17-22$.

Kurup, V., Shen, H., Banerjee, B., 2000. Respiratory fungal allergy. Microbes and Infection 2, 1101-1110.

Lee, C.T., Chuang, M.T., Chan, C.C., Cheng, T.J., Huang, S.L., 2006. Aerosol characteristics from the Taiwan aerosol supersite in the Asian yellow-dust periods of 2002. Atmospheric Environment 40, 3409-3418.

Lewis, S.A., Corden, J.M., Forster, G.E., Newlands, M., 2000. Combined effects of aerobiological pollutants, chemical pollutants and meteorological conditions on asthma admissions and A \& E attendances in Derbyshire UK, 1993-96. Clinical and Experimental Allergy 30, 1724-1732.

Lin, W.H., Li, C.S., 2000. Associations of fungal aerosols, air pollutants, and meteorological factors. Aerosol Science and Technology 32, 359-368.

Lu, Y.C., Tzeng, J.C., Huang, S.G., 1969. Air-borne fungi in Taipei city. Chinese Journal of Microbiology 2, 102-111.

Lugauskas, A., Sveistyte, L., Ulevicius, V., 2003. Concentration and species diversity of airborne fungi near busy streets in Lithuanian urban areas. Annals of Agricultural and Environmental Medicine 10, 233-239.

Mezzari, A., Perin, C., Santos, S.J., Bernd, L., 2002. Airborne fungi in the city of Porto Alegre, Rio Grande do Sul, Brazil. Revista do Instituto de Medicina Tropical de Sao Paulo 44, 269-272.

Mitakakis, T.Z., Guest, D.I., 2001. A fungal spore calendar for the atmosphere of Melbourne, Australia, for the year 1993. Aerobiologia 17, 171-176.

Newson, R., Strachan, D., Corden, J., Millington, W., 2000. Fungal and other spore counts as predictors of admissions for asthma in the Trent region. Occupational and Environmental Medicine 57, 786-792.

Ross, M.A., Persky, V.W., Scheff, P.A., Chung, J., Curtis, L., Ramakrishnan, V., Wadden, R.A., Hryhorczuk, D.O., 2002. Effect on ozone and aeroallergens on the respiratory health of asthmatics. Archives of Environmental Health 57, 568-578.

Sabariego, S., Diaz de la Guardia, C., Alba, F., 2000. The effect of meteorological factors on the daily variation of airborne fungal spores in Granada (southern Spain). International Journal of Biometeorology 44, 1-5.

Singh, B.P., Singh, A.B., Nair, P.K.K., Gangal, S.V., 1987. Survey of airborne pollen and fungal spores at Dehra Dun, India. Annals of Allergy 59, 229-234.

Stennett, P.J., Beggs, P.J., 2004. Alternaria spores in the atmosphere of Sydney, Australia, and relationships with meteorological factors. International Journal of Biometeorology 49, 98-105.

Troutt, C., Levetin, E., 2001. Correlation of spring spore concentrations and meteorological conditions in Tulsa, Oklahoma. International Journal of Biometeorology 45, 64-74.

Tseng, H.Y., Chen, Z.C., 1979. The fungal air spora of Taipei as determined by the agar plate method. Taiwania 24, 54-63.

Vittal, B.P.R., Krishnamoorthi, K., 1988. A census of airborne mold spores in the atmosphere of the city of Madras, India. Annals of Allergy 60, 99-101.

Weber, R.W., 2003. Meteorologic variables in aerobiology. Immunology and Allergy Clinics of North America 23, 411-422.

Willeke, K., Macher, J.A., 1999. Air sampling. In: Macher, J. (Ed.), Bioaerosols: Assessment and Control. American 
Conference of Governmental Industrial Hygienists (ACGIH), Cincinnati, OH, pp. 11:1-11:25.

Wu, P.C., Tsai, J.C., Li, F.C., Lung, S.C., Su, H.J., 2004. Increased levels of ambient fungal spores in Taiwan are associated with dust events from China. Atmospheric Environment 38, 4879-4886.
Zureik, M., Neukirch, C., Leynaert, B., Liard, R., Bousquet, J., Neukirch, F., 2002. Sensitisation to airborne moulds and severity of asthma: cross sectional study from European Community respiratory health survey. British Medical Journal 325, 411-414. 